\title{
Long-term, low-dose immunosuppression for myasthenia does not affect collateral, asymptomatic sclerosing cholangitis
} \author{
colaterais na colangite esclerosante assintomática \\ Josef Finsterer ${ }^{1}$, Sonja Höflich² \\ ${ }^{1}$ Krankenanstalt Rudolfstiftung, Vienna, Danube University Krems, Krems; \\ ${ }^{2}$ Neurological Department, Krankenanstalt Rudolfstiftung, Vienna, Austria, Europe. \\ Correspondence: Josef Finsterer; Postfach 20;w 1180 Vienna, Austria - Europe; E-mail: fifigs1@yahoo.de \\ Conflict of interest: There is no conflict of interest to declare. \\ Received 18 July 2011; Received in final form 16 August 2011; Accepted 23 August 2011.
}

Imunossupressão com baixa dose por períodos longos não apresenta efeitos

Myasthenia gravis (MG) may be associated with other autoimmune diseases, including primary biliary cirrhosis ${ }^{1}$ or primary sclerosing cholangitis (PSC) $)^{2}$, which may complicate or prohibit liver-toxic immunosuppression. Here we show that immunosuppression must be applied with caution, but it is effective over five years if the dosage is adapted to a tolerable amount.

MG was diagnosed in a 76-years-old Caucasian female upon ptosis, fatigability, ophthalmoparesis, dysphagia, raised acetylcholine-receptor (AchR)-antibodies, decremental response to nerve stimulation, and a positive edrophonium test in December, 2005. Liver function parameters were increased (Fig 1). The patient experienced a first myasthenic crisis under cholinergic medication after the initiation of amlodipine, during which liver function parameters markedly increased and a thymoma B3 was resected without chemotherapy.

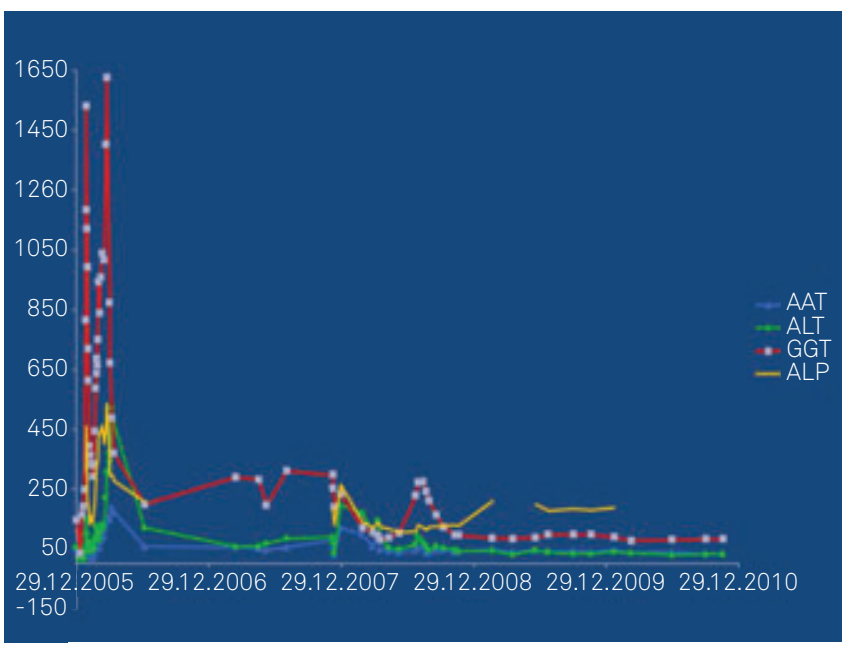

Fig 1. Liver function parameters. Course of asparate-amino transferase (AAT), alanine transaminase (ALT), gamma-glutamyl transaminase (GGT), and alkaline phosphatase (ALP) over five years in the presented patient. Liver function parameters reached excessively high levels, particularly during the three myasthenic crises at onset (left panel).
After adding prednisolone $(25 \mathrm{mg} / \mathrm{d})$ and azathioprine (AZT) $(150 \mathrm{mg} / \mathrm{d})$, she had a second and third myasthenic crisis and a further peak of liver transaminases (Fig 2). Diagnostic workup of liver dysfunction resulted in the diagnosis of PSC. AZT was discontinued and ursodesoxycholic acid was added. After two years (December, 2007), there was continuous increase in the AchR-antibody-titers, and reduction of prednisolone, a fourth myasthenic crisis occurred during an infection. After a fifth myasthenic crisis in March, 2008, it was decided to restart AZT despite PSC, but reactive increase in liver function parameters prompted the reduction of azathioprine from 100 to $50 \mathrm{mg}$. Since this dosage was below the recommended one (1.5 to $2 \mathrm{mg} / \mathrm{kgBW}$ ), AZT was increased to $87.5 \mathrm{mg} / \mathrm{d}$, which is equivalent to $1.5 \mathrm{mg} / \mathrm{kgBW}$. Prednisolone was discontinued after three years (December, 2008). Close monitoring

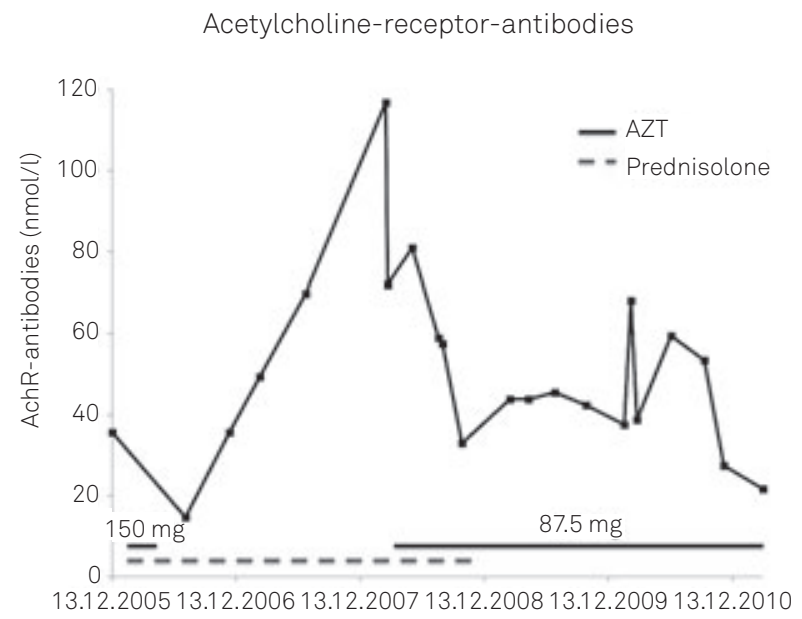

Fig 2. Acetylcholine-receptor-antibodies. Course of acetylcholine-receptor antibodies (AchR-ab) over five years, showing a positive effect of immunosuppression at onset and after the fifth myasthenic crisis (right panel). 
liver function parameters remained constantly elevated but in a tolerable range, without sudden increases, as previously described (Fig 1). AchR-antibodies had their ups and downs, however they also remained stable until the last follow-up in March, 2011 (Fig 2). Since the detection of PSC, the patient has never complained about liver symptoms. Total bilirubine did not exceed a maximal value of $3.0 \mathrm{mg} / \mathrm{dL}$ during five years. Since the last myasthenic crisis, she remained clinically stable, with a persistent slight ptosis on the right side.

PSC is a chronic, inflammatory disease of the bile ducts, complicated by fatigue, pruritus, fibrotic biliary strictures, liver cirrhosis, and liver failure necessitating liver transplantation, cholangiocarcinoma, or colorectal cancer ${ }^{3}$. The etiology of PSC is unknown but autoimmune mechanisms and genetic factors seem to play a pathogenetic role ${ }^{3}$. Although there is no causative treatment yet available, patients may profit from endoscopic therapy of biliary stenoses and inflammatory bowel disease ${ }^{4}$.
The presented report shows that in case of $\mathrm{MG}$ and collateral PSC, liver-toxic immunosuppression with AZT is tolerable and effective even over a longer period of time if the dosage is adapted according to the impaired liver functions. Low-dose AZT has a sufficient therapeutic effect on MG without deterioration of PSC. Possibly, AZT was beneficial even for PSC, since the patient exclusively required ursodesoxycholic acid, PSC did not progress so far, and AZT has also been recommended as a treatment of PSC ${ }^{5}$. Immunosuppressive agents other than AZT were considered, but they were rejected because AZT is the only approved immunosuppressive drug for MG and since other agents are potentially liver-toxic as well. Continuation of steroids was also considered since they may have a beneficial effect on PSC $^{5}$ and on MG, but they were lastly stopped for their side effects, their ineffectivity on the AchR-antibody titers, and since PSC did not deteriorate after their discontinuation.

\title{
References
}

1. Horigome H, Nomura T, Saso K, et al. Coexistence of primary biliary cirrhosis and myasthenia gravis: a case study. Hepatogastroenterology 2000;47:125-127.

2. FinstererJ, Höflich S.Successful low-dose azathioprine for myasthenia gravis despite hepatopathy from primary sclerosing cholangitis: a case report. J Med Case Reports 2010;4:356.

\footnotetext{
3. Karlsen TH, Schrumpf E, Boberg KM. Primary sclerosing cholangitis. Best Pract Res Clin Gastroenterol 2010;24:655-666.

4. Sinakos E, Lindor K. Treatment options for primary sclerosing cholangitis. Expert Rev Gastroenterol Hepatol 2010;4:473-488.

5. Takiguchi J, Ohira H, Rai T, et al. Autoimmune hepatitis overlapping with primary sclerosing cholangitis. Intern Med 2002;41:696-700.
}

\section{Rare case of carotid artery occlusion due to thrombosis of a giant cerebral aneurysm. The role of cerebral revascularization.}

\author{
Caso raro de oclusão da artéria carótida devido à trombose de um aneurisma cerebral \\ gigante. 0 papel da revascularização cerebral.
}

Rafael de Oliveira Sillero', Valter José Sillero Filho², Gislaine Priscila Momm Zimmermann³

${ }^{1} \mathrm{MD}$, Neurosurgeon-in-chief, Neurosurgery Unit, Regional Hospital of São José, São José SC, Brazil;

${ }^{2} \mathrm{MD}$, Neurosurgeon, Neurosurgery Unit, Regional Hospital of São José, São José SC, Brazil;

${ }^{3} \mathrm{MD}$, Ophthalmologist, Regional Hospital of São José, São José SC, Brazil.

Correspondence: Rafael de Oliveira Sillero; Unidade de Neurocirurgia, Hospital Regional de São José; Rua Adolfo Donato da Silva s/n; $88103-901$ São José SC Brasil; E-mail: rafaelsillero@yahoo.com.br

Conflict of interest: There is no conflict of interest to declare.

Received 16 August 2011; Received in final for 06 September 2011; Accepted 13 September 2011

Spontaneous thrombosis of a giant cerebral aneurysm is a recognized phenomenon, however it becomes rare when the thrombosed aneurysm is associated with the occlusion of its parent artery ${ }^{1,2}$. The best management strategy is not defined yet. Theoretically, it should be directed to alleviating mass effect related symptoms caused by the aneurysm itself and to preventing cerebral ischemia.

We describe a case of carotid artery occlusion and discuss the role of cerebral revascularization. 